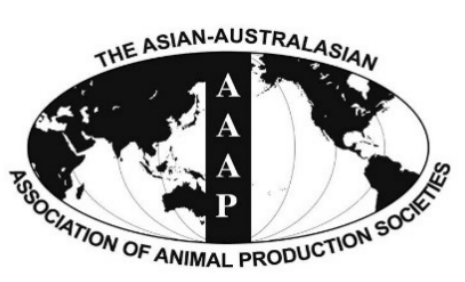

Open Access

Asian Australas. J. Anim. Sci.

Vol. 29, No. 9 : 1247-1255 September 2016

http://dx.doi.org/10.5713/ajas.15.0586

www.ajas.info

pISSN 1011-2367 elSSN 1976-5517

\title{
Seminal Plasma Heparin Binding Proteins Improve Semen Quality by Reducing Oxidative Stress during Cryopreservation of Cattle Bull Semen
}

\author{
Maulikkumar Patel, Vinod K. Gandotra, Ranjna S. Cheema*, Amrit K. Bansal, and Ajeet Kumar \\ Department of Veterinary Gynaecology and Obstetrics, \\ Guru Angad Dev Veterinary and Animal Science University (GADVASU), Ludhiana, Punjab 141004, India
}

\begin{abstract}
Heparin binding proteins (HBPs) are produced by accessory glands. These are secreted into the seminal fluid, bind to the spermatozoa at the time of ejaculation, favour capacitation, acrosome reaction, and alter the immune system response toward the sperm. The present study was conducted with an objective to assess the effect of purified seminal plasma-HBPs (SP-HBPs) on cross bred cattle bull sperm attributes during two phases of cryopreservation: Pre freezing and freezing-thawing. SP-HBPs were purified from pooled seminal plasma by heparin affinity chromatography. Three doses of SP-HBPs i.e. $10,20,40 \mu \mathrm{g} / \mathrm{mL}$ semen were standardized to find out the optimum dose and $20 \mu \mathrm{g} / \mathrm{mL}$ was found to be an optimum dose. Semen as such and treated with SP-HBPs was diluted with sodium citrate-egg yolk diluter and cryopreserved as per the standard protocol. Sperm parameters i.e. motility, viability, Hypo-osmotic swelling test (HOST), acrosome damage, in vitro capacitation and lipid peroxidation were evaluated in SP-HBP treated and untreated (control) semen at both phases of cryopreservation. A considerable variation in percent sperm motility, viability, membrane integrity (HOST), acrosome damage, acrosome reaction and lipid peroxidation was observed at both phases among the bulls irrespective of the treatment. Incubation of neat semen with $20 \mu \mathrm{g} / \mathrm{mL}$ SP-HBP before processing for cryopreservation enhanced the average motility, viability, membrane integrity by $7.2 \%, 1.5 \%, 7.9 \%$, and $5.6 \%, 6.6 \%, 7.4 \%$ in pre-frozen and frozen-thawed semen in comparison to control. There was also an average increase of $4.1 \% / 3.9 \%$ in in vitro capacitation and acrosome reaction in SP-HBPs-treated frozenthawed semen as compared to control. However, binding of SP-HBPs to the sperm declined acrosome damage and lipid peroxidation by $1.3 \% / 4.1 \%$ and $22.1 / 32.7 \mu \mathrm{M} / 10^{9}$ spermatozoa in SP-HBP treated pre-frozen/frozen-thawed semen as compared to control, respectively. Significant $(\mathrm{p}<0.05)$ effects were observed only in motility, HOST and in vitro acrosome reaction. It can be concluded that treatment of neat semen with SP-HBPs before cryopreservation minimized the cryoinjury by decreasing the generation of reactive oxygen species. (Key Words: Seminal Plasma, Heparin Binding Protein [HBP], Cryopreservation, Function Tests, Sperm, Cattle Bulls)
\end{abstract}

\section{INTRODUCTION}

Sperm cryopreservation is an important tool for assisted reproductive techniques and is the most efficient way for storing germ plasm (Olaciregui et al., 2014). Cryopreservation has been applied to various species, including humans, swine, cattle, cats, and dogs (Mota Filho et al., 2014). Although sperm cryopreservation preserves sperm motility, metabolic functions, and fertility, but, still the freeze-thawing process causes irreversible damage to

\footnotetext{
* Corresponding Author: Ranjna S. Cheema. Tel: +91-94644 16085, E-mail: ranjna.cheema@gmail.com

Submitted Jul. 10, 2015; Revised Aug. 18, 2015; Accepted Sept. 11, 2015
}

spermatozoa and reduces fertility (Ardon and Saurez, 2013). Even though cryopreservation helps in prolonged storage of semen, but cryo-capacitation is one of the major factors associated with reduced longevity and poor survivability of cryopreserved spermatozoa in female reproductive tract (Watson, 2000), resulting in reduced fertility of frozenthawed semen. Even with optimized protocols, $40 \%$ to $50 \%$ of the sperms do not survive after cryopreservation due to irreversible damage (Watson, 2000). Several studies have focused on identifying damages during freezing and thawing, tests to screen sperm quality of frozen-thawed semen, evaluation of alternative cryoprotectants and other additives, and freezing procedures to improve sperm viability and fertility. Recently, Yoon et al. (2015) proposed 
that freezing/thawing steps are the most critical in cryopreservation and may provide a logical ground to understand the process of cryo-damage.

Currently, many diverse proteins are being tested that may increase the fertilization capability of sperm and heparin binding proteins (HBPs) are among these proteins. HBPs have been viewed as favouring capacitation, acrosome reaction, and altering the immune system response toward the sperm. The HBPs are produced by the accessory glands of the male under the control of androgens (Miller et al., 1990) and secreted within the seminal fluid (Nass et al., 1990). The HBPs bind to the epididymal sperm and increase the ability of the acrosome reaction in response to the heparin and other proteins of the zona pellucida (Ax et al., 2002). Absorption of isolated proteins from the seminal plasma can reduce the damage that cold shock can have on the sperm membrane (Barrios et al., 2000). Mogielnicka-Brzozowska and Kordan (2011) mentioned the possibility of adding specific plasma proteins to sperm for the retention of features responsible for the efficient fertilization after storage. HBPs protect sperm from stress of freezing and thawing and maintained intracellular protein homeostasis (Shi et al., 1998). HBPs also protect sperm from lipid peroxidation during cryopreservation (Kumar et al., 2008). Preliminary studies were done by AlvarezGallardo et al. (2013) with the recombinant proteins indicated that addition of rFAA and rTIMP-2 to semen before cryopreservation help stabilize the acrosome membrane of the bovine sperm by decreasing post-thaw acrosome damage. Hence the present study was conducted with objective to assess the effect of HBP on sperm function tests at pre-freeze and frozen-thawed phases of cryopreservation.

\section{MATERIALS AND METHODS}

\section{Procurement of semen sample}

Three ejaculates from each of six healthy cross cattle bulls $($ Holstein-Fresian $\times$ Red Dane $\times$ Sahiwal) were procured from GADVASU, Dairy Farm and Semen bank, Bhattian, Khanna, Ludhiana, India. The bulls were kept under loose housing system (covered area, $3.6 \mathrm{~m} \times 3.0 \mathrm{~m}$ and uncovered area, $7.5 \mathrm{~m} \times 3.0 \mathrm{~m}$ ) and standard feeding schedule along with ad libitum green fodder and water availability and standard management conditions. Semen was collected twice a week through artificial vagina method. None of the bulls selected for this study had any preceding physical abnormalities.

A good quality fresh ejaculates (1 to $2 \mathrm{~mL}$ ) with minimum initial motility of $\geq 60 \%$, mass activity of $3+$ to $4+$, abnormal morphology of $\leq 25 \%$ and sperm concentration of $>750 \times 10^{6}$ sperms $/ \mathrm{mL}$ of each bull were processed for cryopreservation. Seminal plasma was separated by centrifuging pooled semen of six bulls at 3,000 rpm for 5 minutes and was stored at $-20^{\circ} \mathrm{C}$ till use.

\section{Purification of HBPs by affinity chromatography}

Sepharose (Sigma-Aldrich) was activated and heparin was bound as per the protocol of Farooqui (1980). The chromatography glass column $(28 \mathrm{~mm} \times 70 \mathrm{~mm})$ was packed with heparin-sepharose media up to the mark at the top of the column and allowed to settle for 3 to $4 \mathrm{~h}$. Thereafter, the column was equilibrated for $1 \mathrm{~h}$ with $10 \mathrm{mM}$ Tris $\mathrm{HCl}(\mathrm{pH}$ 7.4). About $1.0 \mathrm{~mL}$ of pooled seminal plasma (filtered through $0.22 \mu$ filter) was loaded and circulated through the column for 15 minutes for absorption of HBPs to the heparin bound resins. The non-HBPs were washed out with $10 \mathrm{mM}$ Tris $\mathrm{HCl}$ and the HBPs were eluted with $1 \mathrm{M} \mathrm{NaCl}$ at a flow rate of $1 \mathrm{~mL} / \mathrm{min}$ in the tubes racked in a fraction collector. The recovered HBPs fractions were pooled in agreement with the observed curve, obtained from optical density $(280 \mathrm{~nm})$, detected by UV monitor, attached to the fraction collector (Manaskova et al., 2002). The pooled fractions of HBPs were concentrated by spinning through protein concentrators (Millipore, Billerica, MA, USA, 3 $\mathrm{kDa}$ ) and analyzed for protein content (Lowry et al., 1951).

\section{Conjugation of fluorescein isothiocyanate fluorochrome with purified $\mathrm{HBP}$ and confirmation of incorporation of SP-HBP to semen}

Conjugation of fluorescein isothiocyanate (FITC) fluorochrome to SP-HBPs was done by using a kit (Life technology, Carisbad, CA, USA) as per the protocol provided with the kit. About $20 \mu \mathrm{g}$ of purified HBPs was added to $1.0 \mathrm{~mL}$ of neat semen and incubated at $37^{\circ} \mathrm{C}$ for 20 minutes. Semen was washed thrice with phosphate buffered saline (PBS), $\mathrm{pH} 7.4$ by centrifugation at 3,000 rpm for 5 min. Pellet was suspended in $1.0 \mathrm{~mL}$ of PBS and a drop of semen on a glass slide covered with coverslip was observed at $400 \times$ under fluorescence microscope (Olympus, Shinjuku, Tokyo, Japan) using blue filter at $480 \mathrm{~nm}$.

\section{Dilution and cryopreservation of semen}

Three doses of SP-HBPs i.e. 10, 20, $40 \mu \mathrm{g} / \mathrm{mL}$ semen were standardized to find out the optimum dose and 20 $\mu \mathrm{g} / \mathrm{mL}$ was found to be an optimum dose. Semen was divided into two fractions: one fraction, supplemented with SP-HBP and other as such (control), were incubated at $37^{\circ} \mathrm{C}$ for $20 \mathrm{~min}$. After incubation, both fractions were diluted with sodium citrate extender. The pre-freezing sample was kept at $4{ }^{\circ} \mathrm{C}$ in cold handling cabinet for equilibration and aliquot for freezing was filled and sealed by manual filling and sealing method. The filled and sealed straws were cryopreserved in liquid nitrogen by following standard procedure. Semen at pre-freeze and frozen-thaw phase was analyzed for sperm function (motility, viability and Hypo- 
osmotic swelling test [HOST]), acrosome damage, acrosome reaction and lipid peroxidation [LPO]) as detailed below.

\section{Individual motility}

About $10 \mu \mathrm{L}$ of semen was placed on a pre-warmed $\left(37^{\circ} \mathrm{C}\right)$ glass slide, covered with a cover slip and placed on the pre-warmed stage (Magnus Mumbai, Maharashtra, India) attached to a phase contract microscope (Olympus CX21FS1, Japan). Linear progressive motility was assessed by subjective method viewing 10 fields with the aid of closed-circuit television attached to the microscope $(400 \times)$. A total of 200 spermatozoa were observed under phase contrast microscope (Olympus, Japan) at $400 \times$ in different fields and percentage of motile spermatozoa was calculated.

\section{Sperm viability}

Sperm viability was assessed by Syber green/propium iodide (Life technologies staining kit, USA). A total of 200 live (green) and dead (red) spermatozoa were counted in different fields and percentage of viability was calculated (Figure 1).

\section{Hypo-osmotic swelling test}

Briefly, $10 \mu \mathrm{L}$ of semen was incubated in $100 \mu \mathrm{L}$ of hypo-osmotic solution at $37^{\circ} \mathrm{C}$ for $30 \mathrm{~min}$. A total of 150 spermatozoa with coiled and un-coiled tails were counted in different fields (Jeyendran et al., 1984). A control was also run in PBS ( $\mathrm{pH}$ 7.4). The number of spermatozoa with coiled tailed/swollen heads in PBS was deducted from the number in hypo-osmotic solution and the resultant figure was taken as the Hypo-osmotic swelling (HOS)-reactive

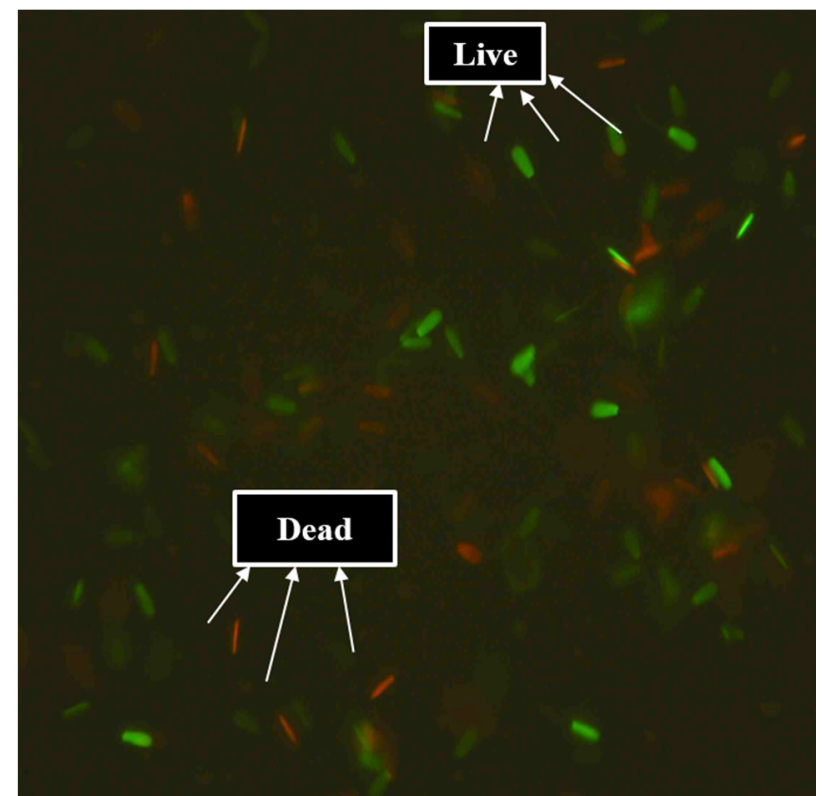

Figure 1. Cattle bull spermatozoa stained with syber green/propidium iodide $(400 \times)$.

spermatozoa.

\section{Acrosomal damage}

Acrosome damage was assessed by chlortetracycline cysteine stain (CTC, Figure 2) (Ward and Storey, 1984). Briefly $25 \mu \mathrm{L}$ of sperm suspension was mixed with $25 \mu \mathrm{L}$ of $750 \mathrm{mM} \mathrm{CTC}$ in $20 \mathrm{mM}$ Tris-HCL, $130 \mathrm{mM} \mathrm{NaCl}$ and 5 $\mathrm{mM}$ cystein, incubated at $37^{\circ} \mathrm{C}$ for $30 \mathrm{~min}$. After adding $100 \mu \mathrm{L}$ of $12.5 \%$ paraformaldehyde and one drop of $0.22 \mathrm{M}$ 1, 4-Diazabicyclo[2.2.2]octane, a drop of sperm suspension was observed under fluorescence microscope (Olympus,
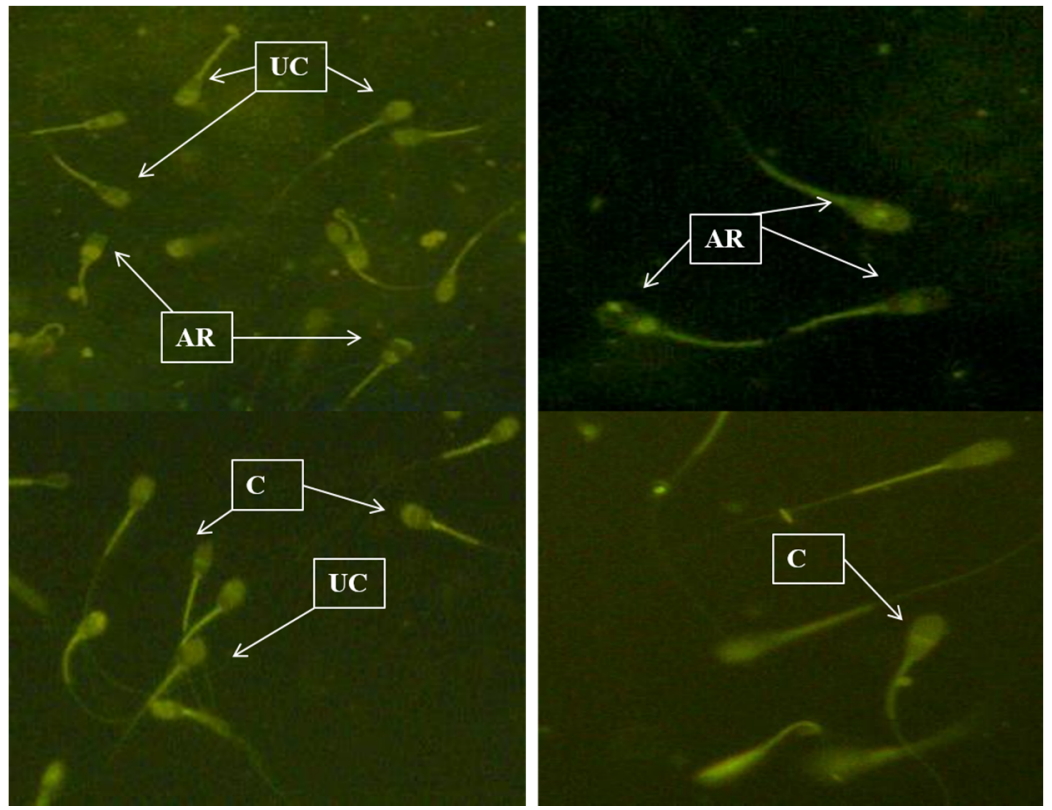

Figure 2. CTC staining of acrosome damage and in vitro capacitated/acrosome reacted cattle bull spermatozoa (400 $\times$ ). CTC, chlortetracycline cysteine; UC, uncapacitated; C, capacitated; AR, acrosome reacted. 


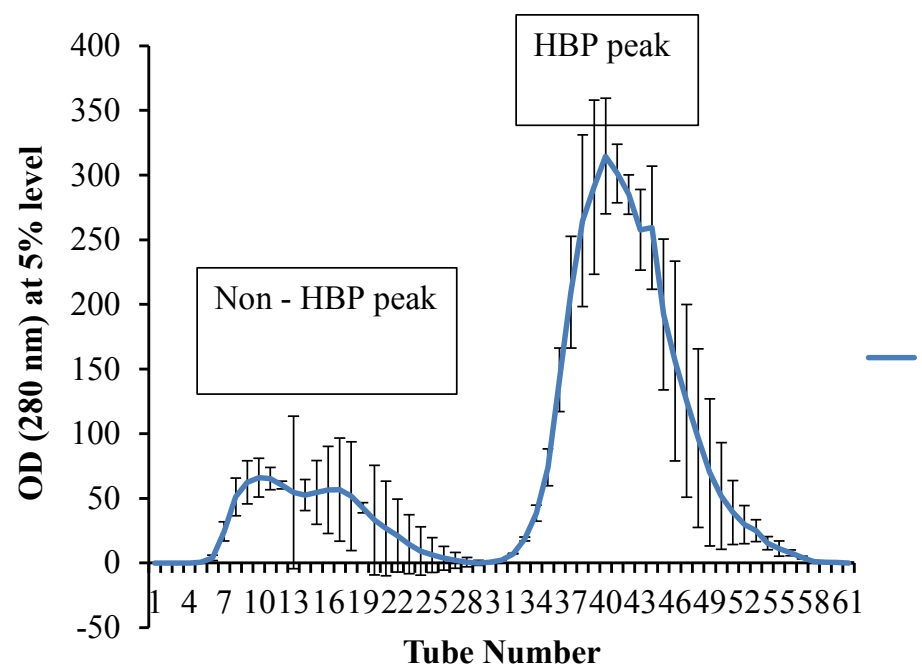

Figure 3. Graphic image of heparin-binding and non-heparin-binding proteins in seminal plasma of cross bred cattle bulls separated on heparin-affinity chromatography.

Japan) at $400 \times$ using blue filter at $480 \mathrm{~nm}$. At least 200 spermatozoa with normal (whole sperm head with bright fluorescence) and cryo capacitated sperm (acrosome-intact sperm with fluorescence ring at equatorial segment) and acrosome-reacted (sperm with fluorescence on postacrosomal region) were counted in different fields at $400 \times$ and percentage of cryo-capacitated and acrosomereacted spermatozoa was calculated (Figure 2).

\section{In vitro capacitation/acrosome reaction}

Frozen-thawed spermatozoa washed twice with tyrode albumin lactate pyruvate medium (TALP, $92.9 \mathrm{mM} \mathrm{NaCl}, 4$ $\mathrm{mM} \mathrm{KCl}, \quad 25.9 \mathrm{mM} \quad \mathrm{NaHCO}_{3}, \mathrm{Na}_{2} \mathrm{HPO}_{4}, \quad 10 \mathrm{mM}$ $\mathrm{CaCl}_{2} \cdot 2 \mathrm{H}_{2} \mathrm{O}, 0.5 \mathrm{mM} \quad \mathrm{MgCl}_{2} \cdot 6 \mathrm{H}_{2} \mathrm{O}, 1.3 \mathrm{mM}$ sodium pyruvate, $7.6 \mathrm{mM}$ sodium lactate and $20 \mathrm{mM} 4-2$ hydroxyethyl-1-piperazineethanesulfonic acid, $\mathrm{pH} 7.4$ were subjected to swim up and only motile spermatozoa were incubated in TALP supplemented with $0.6 \%$ bovine serum albumin, $5 \mathrm{mM}$ glucose and 165 units of heparin for $4 \mathrm{hrs}$ at $37^{\circ} \mathrm{C}$ in an incubator (Fraser et al., 1995). Capacitation/acrosome reaction was assessed by counting 200 spermatozoa in CTC stained slides under fluorescence microscope at $400 \times$ (Olympus, Japan).

\section{Lipid peroxidation}

Lipid peroxidation was estimated by the end point generation of malondialdehyde (MDA) determined by the thiobarbituric acid (TBA) test (Buege and Steven, 1978). Briefly, extended spermatozoa ([40 to 70$] \times 10^{6}$ cells) in 0.5 $\mathrm{mL}$ of cold $10 \%(\mathrm{wt} / \mathrm{vol})$ chilled trichloroacetic acid to proliferate proteins. The precipitate was pelleted by centrifugation $(6,000 \mathrm{rpm}$ for $10 \mathrm{~min})$ and $1 \mathrm{~mL}$ of $0.375 \%$ (wt/vol) TBA was added to the supernatant and kept in a boiling water bath at $100^{\circ} \mathrm{C}$ for 10 minutes. After cooling, the absorbance was read at $532 \mathrm{~nm}$ (UV-VIS spectrophotometer, systronics, Ahmedabad, Gujrat, India).

MDA production was calculated by the formula:

[OD at $532 \mathrm{~nm} \times$ volume of assay mixture]/[molar extinction coefficient* ${ }^{*}$ volume of sample]

$*$ Molar extinction coefficient $=\left(1.56 \times 10^{5} \mathrm{M}-1 \mathrm{C}-1\right)$

\section{Statistical analysis}

The data is presented as mean \pm standard error of the mean and analyses were performed with CPCS1 program package. One way analysis of variance was applied to evaluate the level of significance at $5 \%$ between treatments.

\section{RESULTS AND DISCUSSION}

Purification of HBPs from seminal plasma and verification of binding of SP-HBP to spermatozoa

Graphic image of HBP purified from pooled seminal plasma of cross-bred bulls is shown in Figure 3, which indicated two peaks of unbound (non-HBP) and bound proteins (HBP). Addition of $20 \mu \mathrm{g} / \mathrm{mL}$ of SP-HBP to neat semen and incubation at $37^{\circ} \mathrm{C}$ for $20 \mathrm{~min}$ before cryopreservation resulted in its binding mainly to head and mid piece. But binding was more on post-acrosomal cap in majority of the spermatozoa (Figure 4). A study done by Cheema et al. (2015) on natural localization of HBPs in cross-bred bull spermatozoa using anti-AZU-1 revealed that these proteins are mainly localized on acrosomal cap.

\section{Effect of SP-HBP on sperm function tests}

Standardization of dose of SP-HBP: Effects of different doses of SP-HBP on percent motility, viability, HOST, acrosome damage, in vitro capacitation and LPO in prefreeze and frozen-thaw semen are given in Table 1. Individual motility (\%), viability (\%), HOST (\%) were 


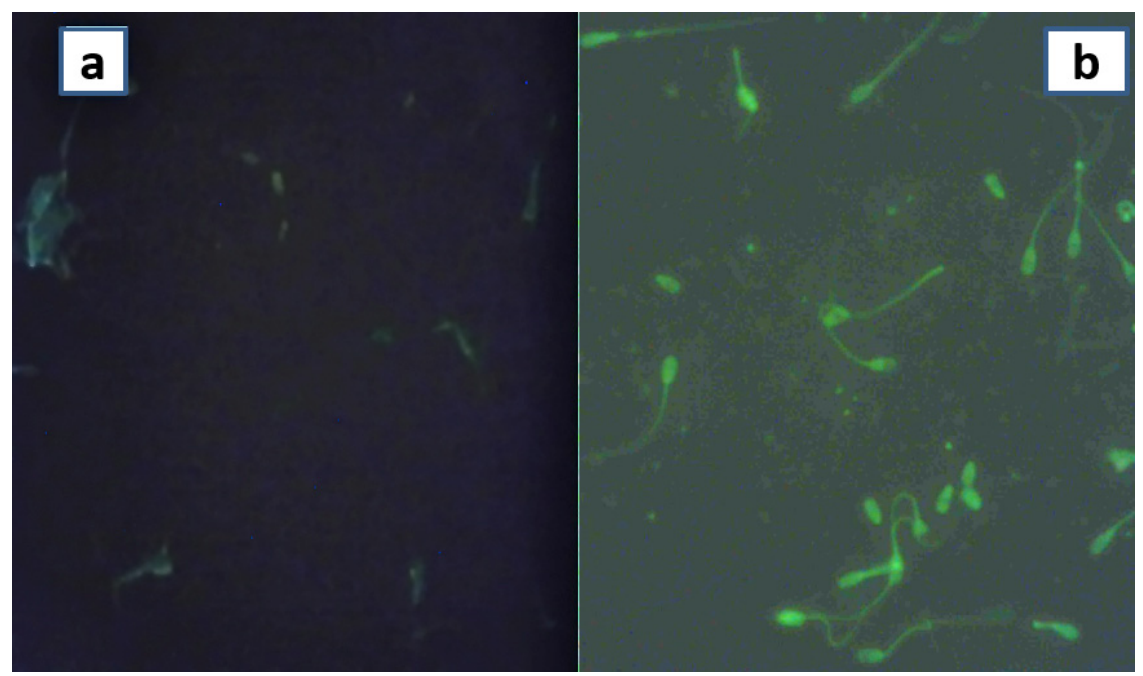

Figure 4. Visualization of binding of SP-HBP to spermatozoa (400×). (a) control (Semen incubated without SP-HBP), and (b) treated (Neat semen incubated with SP-HBP). SP-HBP, seminal plasma-heparin binding protein.

found to be higher in pre-freeze and post-thaw semen supplemented with $20 \mu \mathrm{g} / \mathrm{mL}$ of SP-HBP as compared to 0 , 10 , and $40 \mu \mathrm{g}$ of SP-HBP. Percentage of in vitro capacitated/acrosome reacted spermatozoa was higher only in frozen-thawed semen supplemented with $20 \mu \mathrm{g} / \mathrm{mL} \mathrm{SP-}$ $\mathrm{HBP}$ as compared to 0,10 , and $40 \mu \mathrm{g}$. Acrosome damage $(\%)$ and MDA $\left(\mu \mathrm{M} / 10^{9}\right.$ spermatozoa) showed reduction in semen supplemented with $20 \mu \mathrm{g} / \mathrm{mL}$ of SP-HBP in comparison to 0,10 , and $40 \mu \mathrm{g}$ SP-HBP at both phases of cryopreservation. Increase in motility, viability, in vitro acrosome reaction and decrease in LPO (MDA) in semen supplemented with SP-HBP was statistical significant $(\mathrm{p}<0.05)$. Manjunath et al. (2002) also suggested that at a greater concentration of bovine seminal plasma proteins, more cholesterol and phospholipids are removed from the sperm membrane, resulting in its destabilization that decreases sperm resistance to cold shock and freezing.
Harshan et al. (2006) also postulated that higher loss of semen parameters with higher amount of HBP could be due to an increased cholesterol efflux in the spermatozoa which led to more pronounced cryo-damage. Therefore, effects of $20 \mu \mathrm{g} / \mathrm{mL}$ of SP-HBP on semen cryopreservation of six bulls were evaluated.

\section{Effect of $20 \mu \mathrm{g}$ SP-HBP on sperm function and fertility tests of six bulls}

Motility, Viability and HOST: Mean percentage of motile, live and HOS responsive spermatozoa showed a variation among six cross breed bulls, which ranged from $61.7 \% \pm 1.7 \%$ to $70 \pm 2.9 \% ; 55.7 \% \pm 2.8 \%$ to $73.0 \% \pm 6.6 \%$; $16.0 \% \pm 0.7 \%$ to $36.1 \% \pm 8.0 \%$, and $41.7 \% \pm 4.4 \%$ to $58.3 \% \pm 6.7 \% ; 38.2 \% \pm 3.1 \%$ to $59.5 \% \pm 2.2 \% ; 8.8 \% \pm 4.6 \%$ to $27.5 \% \pm 7.5 \%$ at the time of pre-freezing and freezingthawing, respectively (Table 2). Decrease observed in

Table 1. Effect of different doses of affinity purified SP-HBP on sperm function and fertility tests during pre-freeze and frozen-thaw phases of cryopreservation

\begin{tabular}{|c|c|c|c|c|c|c|c|c|}
\hline \multirow{2}{*}{ Sperm parameter } & \multicolumn{4}{|c|}{ Pre-freeze } & \multicolumn{4}{|c|}{ Frozen-thaw } \\
\hline & $\mathrm{C}^{1}$ & 10 & 20 & 40 & $\mathrm{C}$ & 10 & 20 & 40 \\
\hline Motility (\%) & $73.3 \pm 1.7^{\mathrm{a}}$ & $76.7 \pm 1.7^{\mathrm{a}}$ & $83.3 \pm 1.7^{b}$ & $75.0 \pm 0.0^{\mathrm{a}}$ & $45.0 \pm 2.9^{\mathrm{c}}$ & $46.7 \pm 1.7^{\mathrm{c}}$ & $58.3 \pm 4.4^{\mathrm{d}}$ & $48.3 \pm 4.4^{\mathrm{c}}$ \\
\hline Viability (\%) & $68.7 \pm 3.6^{\mathrm{ab}}$ & $61.2 \pm 1.2^{\mathrm{a}}$ & $76.2 \pm 3.5^{\mathrm{a} b}$ & $72.4 \pm 3.1^{\mathrm{b}}$ & $48.7 \pm 8.7^{c}$ & $47.8 \pm 6.2^{\mathrm{c}}$ & $56.0 \pm 7.6^{\mathrm{c}}$ & $52.4 \pm 8.2^{\mathrm{c}}$ \\
\hline HOST $(\%)$ & $35.3 \pm 2.4^{\mathrm{a}}$ & $38.2 \pm 4.3^{\mathrm{a}}$ & $42.1 \pm 4.1^{\mathrm{a}}$ & $35.72 \pm 2.2^{\mathrm{a}}$ & $35.0 \pm 2.2^{\mathrm{a}}$ & $12.1 \pm 2.4^{b}$ & $18.6 \pm 3.9^{b}$ & $14.4 \pm 3.0^{\mathrm{b}}$ \\
\hline \multicolumn{9}{|l|}{ Acrosome damage $(\%)$} \\
\hline Cryo-Cap & $22.9 \pm 2.6^{\mathrm{a}}$ & $22.1 \pm 1.6^{\mathrm{a}}$ & $23.3 \pm 1.5^{\mathrm{a}}$ & $24.5 \pm 1.8^{\mathrm{a}}$ & $29.2 \pm 2.9^{\mathrm{b}}$ & $28.1 \pm 3.4^{b}$ & $28.4 \pm 1.7^{b}$ & $30.1 \pm 2.4^{b}$ \\
\hline Cryo-AR & $12.1 \pm 4.5^{\mathrm{a}}$ & $10.1 \pm 3.8^{\mathrm{a}}$ & $10.5 \pm 4.4^{\mathrm{a}}$ & $11.5 \pm 4.9^{\mathrm{a}}$ & $16.3 \pm 4.3^{\mathrm{a}}$ & $13.8 \pm 2.8^{\mathrm{a}}$ & $14.6 \pm 3.7^{\mathrm{a}}$ & $17.0 \pm 4.2^{\mathrm{a}}$ \\
\hline \multicolumn{9}{|c|}{ In vitro capacitation/acrosome reaction (\%) } \\
\hline Cap & - & - & - & - & $39.1 \pm 3.4^{\mathrm{a}}$ & $39.4 \pm 2.8^{\mathrm{a}}$ & $44.4 \pm 3.0^{\mathrm{a}}$ & $42.5 \pm 3.2^{\mathrm{a}}$ \\
\hline AR & - & - & - & - & $27.9 \pm 5.8^{\mathrm{a}}$ & $30.1 \pm 6.1^{\mathrm{ab}}$ & $34.0 \pm 5.1^{\mathrm{b}}$ & $33.4 \pm 5.0^{\mathrm{b}}$ \\
\hline $\begin{array}{l}\text { LPO } \\
\text { (MDA, } \mu \mathrm{M} / 10^{9} \text { spermatozoa) }\end{array}$ & $14.7 \pm 5.7^{\mathrm{a}}$ & $12.4 \pm 3.8^{\mathrm{a}}$ & $11.9 \pm 3.6^{\mathrm{a}}$ & $14.5 \pm 4.6^{\mathrm{a}}$ & $50.3 \pm 2.8^{\mathrm{b}}$ & $44.3 \pm 4.1^{\mathrm{bc}}$ & $40.3 \pm 2.6^{\mathrm{c}}$ & $45.3 \pm 4.9^{\mathrm{bc}}$ \\
\hline
\end{tabular}

HOST, hypo-osmotic swelling test; Cap, capacitated; AR, acrosome reacted; LPO, lipid peroxidation; MDA, malondialdehyde.

${ }^{1} \mathrm{C}$, control (0), 10, 20, 40 (Dose of HBP in $\mu \mathrm{g} / \mathrm{mL}$ ).

Superscripts $(a, b, a b, b c)$ indicate the difference at $5 \%$ level of significance within the rows. 
Table 2. Effect of affinity purified SP-HBP on sperm motility, viability and HOST (mean \pm SE) during pre-freeze and frozen-thaw phases of cryopreservation

\begin{tabular}{|c|c|c|c|c|c|c|c|c|c|c|c|c|}
\hline \multirow{3}{*}{ Bull number } & \multicolumn{4}{|c|}{ Motility (\%) } & \multicolumn{4}{|c|}{ Viability } & \multicolumn{4}{|c|}{ HOST } \\
\hline & \multicolumn{2}{|c|}{ Pre-freeze } & \multicolumn{2}{|c|}{ Frozen-thawed } & \multicolumn{2}{|c|}{ Pre-freeze } & \multicolumn{2}{|c|}{ Frozen-thawed } & \multicolumn{2}{|c|}{ Pre-freeze } & \multicolumn{2}{|c|}{ Frozen-thawed } \\
\hline & $\mathrm{C}^{1}$ & $\mathrm{~T}^{1}$ & $\mathrm{C}$ & $\mathrm{T}$ & $\mathrm{C}$ & $\mathrm{T}$ & $\mathrm{C}$ & $\mathrm{T}$ & $\mathrm{C}$ & $\mathrm{T}$ & $\mathrm{C}$ & $\mathrm{T}$ \\
\hline 1 & $70.0 \pm 0.0$ & $80.0 \pm 0.0$ & $58.3 \pm 3.4$ & $66.6 \pm 2.9$ & $73.0 \pm 6.6$ & $79.6 \pm 4.5$ & $59.5 \pm 2.2$ & $64.8 \pm 2.7$ & $30.6 \pm 3.7$ & $36.2 \pm 3.3$ & $18.1 \pm 3.2$ & $25.1 \pm 4.9$ \\
\hline 2 & $70.0 \pm 2.9$ & $78.3 \pm 3.3$ & $55.0 \pm 2.9$ & $61.7 \pm 1.7$ & $69.1 \pm 7.5$ & $76.9 \pm 5.8$ & $54.9 \pm 7.1$ & $61.6 \pm 6.0$ & $32.5 \pm 8.1$ & $54.6 \pm 2.5$ & $16.9 \pm 5.9$ & $27.8 \pm 4.8$ \\
\hline 3 & $68.3 \pm 4.4$ & $73.3 \pm 4.4$ & $50.0 \pm 5.8$ & $56.6 \pm 4.4$ & $65.9 \pm 3.8$ & $71.0 \pm 3.6$ & $50.4 \pm 8.8$ & $56.4 \pm 6.1$ & $36.1 \pm 8.0$ & $46.3 \pm 6.2$ & $27.5 \pm 7.5$ & $35.3 \pm 5.7$ \\
\hline 4 & $61.7 \pm 1.7$ & $70.0 \pm 2.9$ & $45.0 \pm 2.9$ & $50.0 \pm 2.9$ & $61.3 \pm 2.1$ & $67.0 \pm 1.0$ & $43.0 \pm 7.2$ & $47.2 \pm 7.2$ & $25.3 \pm 5.1$ & $30.1 \pm 3.3$ & $17.7 \pm 1.7$ & $20.7 \pm 2.1$ \\
\hline 5 & $63.3 \pm 3.3$ & $68.3 \pm 3.3$ & $41.7 \pm 4.4$ & $43.3 \pm 3.3$ & $55.7 \pm 2.8$ & $59.3 \pm 3.3$ & $38.2 \pm 3.1$ & $44.9 \pm 0.2$ & $16.0 \pm 0.7$ & $22.0 \pm 2.6$ & $8.8 \pm 4.6$ & $12.6 \pm 3.2$ \\
\hline 6 & $65.0 \pm 2.9$ & $71.7 \pm 1.7$ & $46.7 \pm 6.0$ & $51.7 \pm 6.0$ & $65.1 \pm 0.5$ & $69.3 \pm 1.8$ & $48.5 \pm 1.4$ & $59.5 \pm 0.7$ & $21.6 \pm 4.6$ & $32.5 \pm 4.0$ & $12.6 \pm 2.0$ & $24.6 \pm 1.5$ \\
\hline $\begin{array}{l}\text { Combination } \\
\text { factor mean }\end{array}$ & $66.4^{\mathrm{a}}$ & $73.6^{\mathrm{b}}$ & $49.4^{\mathrm{c}}$ & $55.0^{\mathrm{d}}$ & $65.0^{\mathrm{a}}$ & $70.5^{\mathrm{a}}$ & $49.1^{\mathrm{b}}$ & $55.7^{\mathrm{b}}$ & $27.0^{\mathrm{a}}$ & $36.9^{\mathrm{b}}$ & $16.9^{c}$ & $24.3^{\mathrm{a}}$ \\
\hline
\end{tabular}

SP-HBP, seminal plasma-heparin binding protein; HOST, hypo-osmotic swelling test; SE, standard error.

${ }^{1} \mathrm{C}$, control without HBP; T, supplemented with SP-HBP.

Superscripts a, b, c, d indicate the difference at $5 \%$ level of significance within the columns.

percent motility, viability and HOST from pre-freeze to post thaw phase of cryopreservation was significant $(\mathrm{p}<0.05)$. Lessard et al. (2000) were of the opinion that sperm viability decrease by $50 \%$, whereas, fertilizing capacity is affected by a factor of sevenfold after cryopreservation. However, incorporation of SP-HBP to the sperm surface resulted in an increase of $5.0 \%$ to $10.0 \% ; 3.6 \%$ to $7.8 \%$; $4.8 \%$ to $22.1 \%$, and $1.6 \%$ to $8.3 \% ; 4.2 \%$ to $11.0 \% ; 3.0 \%$ to $12.0 \%$ in motile, live and HOS positive spermatozoa at prefreeze and frozen-thaw phase of cryo-preservation as compared to control, respectively. However, increase in only motility and HOST due to supplementation of SP-HBP was significant $(\mathrm{p}<0.05)$ at both phases of cryopreservation. Harshan et al. (2006) revealed that $40 \mu \mathrm{g}$ dose of HBP improved the motility, HOST and cervical mucus penetration test at pre-freeze phase of buffalo semen cryopreservation, but they did not observe positive effect of this dose on frozen-thawed semen. Barrios et al. (2000) also demonstrated that the absorption of isolated proteins from seminal plasma may reduce the cold shock effect.

Acrosome damage: Two stages of acrosome damage were revealed by CTC staining i.e. partial (cryo-capacitated) and complete (cryo-acrosome reacted). These two phases of sperm due to cryo-injury are demonstrated as premature capacitation and spontaneous acrosome reaction (Srivastava et al., 2013). Mean percentage of cryo-capacitated and acrosome reacted spermatozoa showed a variation among the bulls and ranged from $20.1 \% \pm 1.1 \%$ to $30.6 \% \pm 1.5 \%$ and $5.3 \% \pm 0.3 \%$ to $14.3 \% \pm 4.1 \%$ at pre-freeze phase, which was further significantly $(\mathrm{p}<0.05)$ increased to $25.6 \% \pm 4.5 \%$ to $37.5 \% \pm 0.7 \%$ and $10.9 \% \pm 1.3 \%$ to $21.1 \% \pm 0.5 \%$ in frozenthaw phase of cryopreservation in six bulls, respectively (Table 3). Altered mitochondrial function, reduction in motility and failure of chromatin condensation, all of which influence the viability and fertility of sperm have also been reported due to induction of pre-mature acrosome reaction (Watson, 2000; Chaveiro et al., 2006). Acrosomal cap is of utmost importance for fertilization and is related to fertility. Spermatozoa with higher motility cannot be fertile due to acrosomal loss (Raval and Dhami, 2010).

Acrosome is required to undergo biochemical changes in the female reproductive tract before fertilization and

Table 3. Effect of affinity purified SP-HBP on acrosome damage (mean \pm SE) during pre-freeze and frozen-thaw phase of cryopreservation

\begin{tabular}{|c|c|c|c|c|c|c|c|c|}
\hline \multirow{3}{*}{ Bull number } & \multicolumn{4}{|c|}{ Pre-freeze } & \multicolumn{4}{|c|}{ Frozen-thawed } \\
\hline & \multicolumn{2}{|c|}{ Control $^{1}$} & \multicolumn{2}{|c|}{ Treated $^{1}$} & \multicolumn{2}{|c|}{ Control } & \multicolumn{2}{|c|}{ Treated } \\
\hline & Capacitated & $\begin{array}{l}\text { Acrosome } \\
\text { reacted }\end{array}$ & Capacitated & $\begin{array}{l}\text { Acrosome } \\
\text { reacted }\end{array}$ & Capacitated & $\begin{array}{l}\text { Acrosome } \\
\text { reacted }\end{array}$ & Capacitated & $\begin{array}{c}\text { Acrosome } \\
\text { reacted }\end{array}$ \\
\hline 1 & $20.2 \pm 3.4$ & $14.3 \pm 4.1$ & $21.2 \pm 3.6$ & $11.7 \pm 3.7$ & $25.6 \pm 4.5$ & $16.8 \pm 3.6$ & $23.6 \pm 3.4$ & $15.8 \pm 3.5$ \\
\hline 2 & $25.1 \pm 3.8$ & $9.6 \pm 2.1$ & $25.2 \pm 3.7$ & $8.5 \pm 2.8$ & $30.8 \pm 3.3$ & $13.3 \pm 2.0$ & $21.3 \pm 0.8$ & $4.9 \pm 0.6$ \\
\hline 3 & $20.1 \pm 1.1$ & $5.3 \pm 0.3$ & $20.3 \pm 0.8$ & $4.9 \pm 0.6$ & $26.1 \pm 1.4$ & $10.9 \pm 1.3$ & $26.3 \pm 1.4$ & $10.1 \pm 0.8$ \\
\hline 4 & $22.9 \pm 1.0$ & $6.6 \pm 0.1$ & $24.4 \pm 0.7$ & $5.2 \pm 0.1$ & $32.9 \pm 0.8$ & $14.0 \pm 3.1$ & $33.9 \pm 0.4$ & $12.4 \pm 2.6$ \\
\hline 5 & $30.6 \pm 1.5$ & $9.0 \pm 0.4$ & $29.6 \pm 0.9$ & $10.8 \pm 0.7$ & $37.5 \pm 0.7$ & $13.5 \pm 2.0$ & $35.0 \pm 1.2$ & $15.0 \pm 2.0$ \\
\hline 6 & $21.5 \pm 1.0$ & $14.1 \pm 2.1$ & $22.1 \pm 0.5$ & $12.2 \pm 2.6$ & $29.5 \pm 0.6$ & $21.1 \pm 0.5$ & $29.6 \pm 0.2$ & $19.8 \pm 1.4$ \\
\hline $\begin{array}{r}\text { Combination } \\
\text { factor mean }\end{array}$ & $23.4^{\mathrm{a}}$ & $9.8^{\mathrm{a}}$ & $23.08^{\mathrm{a}}$ & $8.8^{\mathrm{a}}$ & $30.4^{\mathrm{b}}$ & $14.9^{\mathrm{bc}}$ & $28.2^{\mathrm{bc}}$ & $13.0^{\mathrm{c}}$ \\
\hline
\end{tabular}

SP-HBP, seminal plasma-heparin binding protein; SE, standard error.

${ }^{1}$ Control, without HBP); Treated, supplemented with HBP.

Superscripts a, b, bc, c indicates the difference at 5\% level of significance within column. 
premature loss of acrosome and hence loss of enzymes will affect the fertilization process. Supplementation of SP-HBP to cattle bull semen resulted in a non-significant $(\mathrm{p}<0.05)$ reduction of $1.0 \%$ to $1.4 \%$ and $0.6 \%$ to $17.9 \%$ in acrosome damage at pre-freeze and frozen-thaw phase, respectively. Our study revealed a reduction in cold shock effect on treating the spermatozoa with SP-HBP. Result of a study by Mogielnicka-Brzozowska et al. (2011) also indicated that zona binding proteins of boar seminal plasma have a shielding effect on the plasma membrane and the acrosome of spermatozoa by protecting their structures against the damage caused by cold shock. Mogielnicka-Brzozowska and Kordan (2011) mentioned that addition of specific plasma protein to sperm probably may retain the features responsible for the efficient fertilization after storage.

In vitro capacitation and acrosome reaction: A variation in response of frozen-thawed spermatozoa to in vitro capacitation and acrosome reaction was also observed irrespective of treatment among the six bulls. Incubation of frozen thawed spermatozoa of six bulls in TALP energy medium resulted in $36.6 \% \pm 2.1 \%$ to $45.6 \% \pm 1.8 \%$ capacitated and $23.9 \% \pm 2.2 \%$ to $31.7 \% \pm 1.7 \%$ acrosome reacted spermatozoa (Table 4). Incorporation of SP-HBP enhanced the percentage of capacitated $(41.9 \% \pm 1.7 \%$ to $48.5 \% \pm 0.2 \%)$ and acrosome reacted $(26.6 \% \pm 2.5 \%$ to $33.5 \% \pm 5.4 \%$ ) spermatozoa in frozen-thawed semen of six bulls. It indicated a significant $(p<0.05)$ increase of $6.2 \%$ to $11.4 \%$ in capacitated/acrosome reacted spermatozoa upon binding of SP-HBP to the sperm membrane. Arangasamy (2010) performed in vitro capacitation of stallion spermatozoa in the presence of SP-HBP/heparin and found significant difference in treated and control groups. Heparin and heparin like molecules are known to effectively capacitate bovine sperm. High density lipoproteins (HDL) have also been shown to capacitate bull sperm (Therein et al., 1998) and HDL by binding to the bovine seminal plasma proteins (Manjunath et al., 1988). Addition of purified fraction of 15 to $17 \mathrm{kDa}, 24 \mathrm{kDa}$, and $31 \mathrm{kDa}$ HBPs (Miller et al., 1990) to epididymal sperm revealed the effect of heparin. They further conveyed that fraction containing 24 and $31 \mathrm{kDa}$ proteins possessed greatest activity/unit of protein to induce acrosome exocytosis.

Lipid peroxidation: An increase of 35.8 to 108.1 $\mu$ moles of $\mathrm{MDA} / 10^{9}$ spermatozoa was noticed from prefreeze to freezing-thawing process of cryopreservation (Table 5). MDA has been used in biochemical assays to monitor the degree of peroxidative damage in spermatozoa and exhibited an excellent correlation with the degree to which sperm function is impaired in terms of motility and the capacity for sperm-oocyte fusion (Sidhu et al., 1998). Increase in MDA production due to freezing-thawing was non- significantly ( $\mathrm{p}>0.05)$ less $\left(23.1\right.$ to $86.9 \mu \mathrm{moles} / 10^{9}$ spermatozoa) in semen supplemented with SP-HBP in
Table 4. Effect of affinity purified SP-HBP on in vitro capacitation/acrosome reaction (mean $\pm \mathrm{SE})$ during pre-freeze and frozen-thaw phase of cryopreservation

\begin{tabular}{lccccc}
\hline \multirow{2}{*}{$\begin{array}{c}\text { Bull } \\
\text { number }\end{array}$} & \multicolumn{2}{c}{ Control } & & \multicolumn{2}{c}{ Treated } \\
\cline { 2 - 3 } \cline { 5 - 6 } \cline { 5 - 6 } & Capacitated & $\begin{array}{c}\text { Acrosome } \\
\text { reacted }\end{array}$ & & Capacitated & $\begin{array}{c}\text { Acrosome } \\
\text { reacted }\end{array}$ \\
\hline 1 & $41.7 \pm 1.6$ & $28.3 \pm 5.7$ & & $44.1 \pm 1.6$ & $33.5 \pm 5.4$ \\
2 & $40.9 \pm 0.4$ & $24.4 \pm 2.2$ & & $46.9 \pm 0.6$ & $26.6 \pm 2.5$ \\
3 & $36.6 \pm 2.1$ & $23.9 \pm 2.2$ & & $41.9 \pm 1.7$ & $30.0 \pm 2.5$ \\
4 & $45.6 \pm 1.8$ & $25.0 \pm 3.3$ & & $47.1 \pm 0.5$ & $30.4 \pm 2.9$ \\
5 & $43.0 \pm 0.4$ & $27.0 \pm 2.9$ & & $48.5 \pm 0.2$ & $27.7 \pm 2.1$ \\
6 & $40.0 \pm 2.0$ & $31.7 \pm 1.7$ & & $44.3 \pm 0.5$ & $32.9 \pm 3.7$ \\
Average \pm SE & $41.4^{\mathrm{a}}$ & $26.3^{\mathrm{b}}$ & & $45.5^{\mathrm{c}}$ & $30.2^{\mathrm{d}}$ \\
\hline
\end{tabular}

SP-HBP, seminal plasma-heparin binding protein; SE, standard error. ${ }^{1}$ Control, without HBP; Treated, supplemented with SP-HBP.

Superscripts a, b, c, d indicate the difference at $5 \%$ level of significance within the columns.

comparison to control.

There was a non significant $(\mathrm{p}>0.05)$ decline of 5.8 to $40.1 \mu \mathrm{moles} / 10^{9}$ and 16.3 to $64.7 \mu$ moles $/ 10^{9}$ spermatozoa in pre-frozen and frozen-thawed semen supplemented with SP-HBP, respectively. Karunakaran et al. (2012) added 25 $\mu \mathrm{g}$ of 28 to $30 \mathrm{kDa}$ HBP to the frozen-thawed bull semen in control and $\mathrm{H}_{2} \mathrm{O}_{2}$ treated group and concluded that excessive $\mathrm{H}_{2} \mathrm{O}_{2}$ causes significant increase in LPO levels and 28 to $30 \mathrm{kDa} \mathrm{HBP}$ of sperm membrane helped in controlling the oxidative stress of sperm cells. Kumar et al. (2008) were also of the opinion that HBPs protected the buffalo bull spermatozoa from lipid peroxidation stress during cryopreservation.

Seminal oxidative stress develops as a result of an imbalance between reactive oxygen species and scavenging activities. Spermatozoa are particularly susceptible to the oxidative stress induced damage as their plasma membrane

Table 5. Effect of affinity purified SP-HBP on MDA production $\left(\mu \mathrm{M} / 10^{9}\right.$ spermatozoa, mean $\left.\pm \mathrm{SE}\right)$ during pre-freeze and frozenthaw phase of cryopreservation

\begin{tabular}{lccccc}
\hline \multirow{2}{*}{$\begin{array}{c}\text { Bull } \\
\text { number }\end{array}$} & \multicolumn{2}{c}{ Pre-freeze } & & \multicolumn{2}{c}{ Frozen-thaw } \\
\cline { 2 - 3 } \cline { 5 - 6 } & Control $^{1}$ & Treated $^{1}$ & & Control & Treated \\
\hline 1 & $73.5 \pm 51.3$ & $51.6 \pm 35.0$ & & $112.4 \pm 38.0$ & $94.9 \pm 37.8$ \\
2 & $46.8 \pm 19.4$ & $24.9 \pm 12.8$ & & $83.3 \pm 19.4$ & $60.3 \pm 15.1$ \\
3 & $22.1 \pm 10.3$ & $50.2 \pm 33.4$ & & $115.2 \pm 34.1$ & $98.9 \pm 31.6$ \\
4 & $72.9 \pm 20.8$ & $32.8 \pm 5.4$ & & $130.3 \pm 47.5$ & $65.6 \pm 16.8$ \\
5 & $97.0 \pm 24.5$ & $62.3 \pm 22.6$ & & $132.8 \pm 49.6$ & $85.4 \pm 31.5$ \\
6 & $51.6 \pm 20.7$ & $45.8 \pm 20.9$ & & $159.7 \pm 69.9$ & $132.7 \pm 51.1$ \\
Combination & $66.7^{\text {ac }}$ & $44.6^{\text {a }}$ & & $122.3^{\text {bd }}$ & $89.6^{\text {cd }}$ \\
factor mean & & & & \\
\cline { 1 - 1 } & & & &
\end{tabular}

SP-HBP, seminal plasma-heparin binding protein; MDA,
malondialdehyde; SE, standard error.

${ }^{1}$ Control, without HBP; Treated, supplemented with SP-HBP.

Superscripts a, ac, bd, cd indicates the difference at $5 \%$ level of significance within the colums. 
contains large quantity of polyunsaturated fatty acids. Cytoplasm of spermatozoa has low concentration of scavenging enzymes (Sharma and Agarwal, 1996). Moreover mature sperm is devoid of cytoplasm and intracellular antioxidant enzymes cannot protect the plasma membrane that surrounds acrosome and tail. Therefore, for their protection spermatozoa depend upon seminal plasma. Small amounts of reactive oxygen species (ROS) have been presented to be required for several functions of spermatozoa, but their excessive levels can negatively impact the quality of spermatozoa and impair the fertilizing capacity (Tvrda et al., 2011). Reactive oxygen species are usually formed during normal enzymatic reaction of inter and intracellular signalling (Agarwal and Allamaneni, 2006). Therefore, declined level of MDA production in the spermatozoa treated with SP-HBP may be due to its interference with enzymatic reaction of inter and intracellular signalling responsible for ROS production.

Oxidative stress affects the fluidity of sperm plasma membrane as well as integrity of DNA in the nucleus (Aitken, 1999). Increase in membrane fluidity leads to sperm capacitation. Therefore, higher level of acrosome damage (cryocapacitation like changes ) observed in frozenthawed spermatozoa as compared to pre-frozen spermatozoa may be due to increase in ROS level during cryopreservation of semen, which was also evidenced from increased level of MDA production. Spermatozoa itself produce small amounts of ROS that are essential to many of physiological process i.e. capacitation, hyperactivation and sperm oocyte fusion (Aitken et al., 2003). Low level of ROS has also been shown to be essential for fertilization, acrosome reaction and motility. Production of higher level of ROS as observed by a rising level of MDA production in frozen-thawed spermatozoa was repressed by addition of SP-HBP. Therefore reduced level of oxidative stress in frozen thawed spermatozoa treated with SP-HBP may be responsible for higher percentage of motile, viable, HOS positive, in vitro capacitated/acrosome reacted spermatozoa and spermatozoa with intact acrosomes in pre-frozen and frozen-thawed semen of six cross bred bulls.

It was observed during the present study that cryopreservation of semen of six bulls resulted in reduced motility, viability, HOST and enhanced acrosome damage/oxidative stress with a variation among the bulls. Such a variation may be attributed to varying concentration of membrane cholesterol. Fresh spermatozoa with higher cholesterol content are expected to resist destabilization of membrane following cryopreservation (Srivastava et al., 2013). Since membrane integrity is altered with cryopreservation, spermatozoa with more cholesterol content prior to cryopreservation will also resist membrane damage and effect of membrane damage and cryocapacitation will be less evident in these bulls (Srivastava et al., 2013). Treatment of semen with SP-HBP improved motility, viability, HOST, acrosome integrity, in vitro capacitation/acrosome reaction by diminishing oxidative stress, but with a variation among the bulls. HBPs are acquired by spermatozoa at the time of ejaculation and have been associated with removal of cholesterol from sperm membrane during capacitation (Therien et al., 2001). Therefore, variation in response of spermatozoa to SP-HBP treatments may also be associated to varying concentration of sperm membrane cholesterol.

Our observations revealed that absorption of SP-HBP to the sperm surface reduced the damage that cold shock can have on the sperm membrane during the process of freezing, consequently as pointed out by Lessard et al. (2000), increase in fertilizing capacity of SP-HBP treated cryopreserved semen should be expected.

\section{CONFLICT OF INTEREST}

We certify that there is no conflict of interest with any financial organization regarding the material discussed in the manuscript.

\section{REFERENCES}

Agarwal, A. and S. Allamaneni. 2006. Oxidative stress and human reproduction. In: Oxidative Stress, Disease and Cancer (Ed. K. K. Singh). Imperial College Press, New York, NY, USA. pp. 687-703.

Aitken, R. J. 1999. The Amoroso lecture the human spermatozoon - a cell in crisis? J. Reprod. Fertil. 115:1-7.

Aitken, R. J., M. A. Baker, and D. Sawyer. 2003. Oxidative stress in the male germ line and its role in the aetiology of male infertility and genetic disease. Reprod. Biomed. Online 7:6570 .

Alvarez-Gallardo, H., M. E. Kjelland, J. F. Moreno, T. H. Welsh, Jr. and R. D. Randel. 2013. Gamete therapeutics: Recombinant protein adsorption by sperm for increasing fertility via artificial insemination. Plos One. 8:e65083.

Arangasamy, A. 2010. Effect of stallion seminal plasma proteins on in-vitro capacitation of equine spermatozoa. Ind. J. Anim. Sci. 80:394-397.

Ardon, F. and S. S. Sauarez. 2013. Cryopreservation increases coating of bull sperm by seminal plasma binder of sperm proteins BSP1, BSP3, and BSP5. Reproduction 146:111-117.

Ax, R. L., H. E. Hawkins, S. K. DeNise, T. R. Holm, and H. M. Zhang. 2002. New developments in managing the bull. In: Factors Affecting Calf Crop: Biotechnology of Reproduction (Eds. M. J. Fields, R. S. Sand, and J. V. Yelich). CRC Press LLC, Boca Raton, FL, USA. pp. 287-295.

Barrios, B., R. Perez-Pe, M. Gallego, A. Tato, J. Osada, T. MuinoBlanco, and J. A. Cebrian-Perez. 2000. Seminal plasma proteins revert the cold-shock damage on ram sperm membrane. Biol. Reprod. 63:1531-1537. 
Buege, J. A. and S. D. Aust. 1978. Microsomal lipid peroxidation. Methods Enzymol. 52:302-310.

Chaveiro, A., L. Machado, A. Frijters, B. Engel, and H. Woelders. 2006. Improvement of parameters of freezing medium and freezing protocol for bull sperm using two osmotic supports. Theriogenology 65:1875-1890.

Cheema, R. S., V. Zodinsanga, and A. K. Bansal. 2015. Characterization and immunolocalization of HBP, FA-1 and TIMP-2 like proteins in cattle bull semen: HBP modification in in vitro capacitated spermatozoa. Theriogenol. Insight 5:5367.

Farooqui, A. A. 1980. Purification of enzymes by heparinsepharose affinity chromatography. J. Chromatogr. A. 184:335345.

Fraser, L. R., L. R. Abeydeera, and K. Niwa. 1995. $\mathrm{Ca}^{2+}-$ Regulating mechanisms that modulate bull sperm capacitation and acrosomal exocytosis as determined by chlortetracycline analysis. Mol. Reprod. Dev. 40:233-241.

Harshan, H. M., L. P. Singh, A. Arangasamy, M. R. Ansari, and S. Umar. 2006. Effect of buffalo seminal plasma heparin binding protein (HBP) on freezability and in vitro fertility of buffalo cauda spermatozoa. Anim. Reprod. Sci. 93:124-133.

Jeyendran, R. S., H. H. Vander-Ven, M. Perez-Pelaez, B. G. Crabo, and L. J. D. Zanevld. 1984. Development of an assay to assess the functional integrity of the human sperm membrane and its relationship to other semen characteristics. J. Repord. Fertil. 70: 219-228.

Karunakaran, M., T. G. Devanathan, K. Kulasekar, P. Sridevi, T. Jawahar, K. Loganatahsamy, A. Dhali, and S. Selvaraju. 2012. Effect of fertility associated protein on oxidative Stress of bovine sperm cells. Ind. J. Anim. Reprod. 33:43-47.

Kumar, A., L. P. Singh, H. M. Harshan, and A. C. Majumdar. 2008. Seminal plasma non-heparin binding proteins (NHBP) reduce the cryoinjury to buffalo cauda epididymal spermatozoa induced by heparin binding proteins (HBP). Anim. Reprod. Sci. 104:220-226.

Lessard, C., S. Parent, P. Leclerc, J. L. Bailey, and R. Sullivan. 2000. Cryopreservation alters the levels of the bull sperm surface protein P25b. J. Androl. 21:700-707.

Lowry, O. H., N. J. Rosenberg, A. L. Farr, and R. J. Randall. 1951. Protein measurement with the folin phenol reagent. J. Biol. Chem. 193:265-275.

Manaskova, P., J. Liberda, M. Ticha, and V. Jonakova. 2002. Isolation of non-heparin-binding and heparin-binding proteins of boar prostate. J. Chromatograph. B. 770:137-143.

Manjunath P., V. Nauc, A. Bergeron, and M. Me'nard. 2002. Major proteins of bovine seminal plasma bind to the low-density lipoprotein fraction of hen's egg yolk. Biol. Reprod. 67:12501258.

Miller, D. J., M. A. Winer, and R. L. Ax. 1990. Heparin-binding proteins from seminal plasma bind to bovine spermatozoa and modulate capacitation by heparin. Biol. Reprod. 42:899-915.
Mogielnicka-Brzozowska, M. and W. Kordan. 2011. Characteristics of selected seminal plasma proteins and their application in the improvement of the reproductive processes in mammals. Pol. J. Vet. Sci. 14:489-499.

Mogielnicka-Brzozowska, M., P. Wysocki, J. Strzezek, and W. Kordan. 2011. Zinc-binding proteins from boar seminal plasma - isolation, biochemical characteristics and influence on spermatozoa stored at $4^{\circ} \mathrm{C}$. Acta Biochim. Pol. 58:171-177.

Mota Filho, A. C., H. V. Silva, T. G. Nunes, M. B. de Souza, L. A. de Freitas, A. A. de Araujo, and L. D. M. da Silva. 2014. Cryopreservation of canine epididymal sperm using ACP-106c and TRIS. Cryobiology 69:17-21.

Nass, S. J., D. J. Miller, M. A. Winer, and R. L. Ax. 1990. Male accessory sex glands produce heparin-binding proteins that bind to cauda epididymal spermatozoa and are testosterone dependent. Mol. Reprod. Dev. 25:237-246.

Olaciregui, M. L. Gil, A. Monton, V. Luno, R. A. Jerez, and J. I. Marti. 2014. Cryopreservation of epididymal stallion sperm. Cryobiology 68:91-95.

Raval, R. J. and A. J. Dhami. 2010. Effect of additives on various spermatozoal attributes of fresh, frozen-thawed and refrigerated semen. Ind. J. Anim. Reprod. 31:33-36.

Sharma, R. K. and A. Agarwal. 1996. Role of reactive oxygen species in male infertility. Urology 48:835-850.

Shi, Y., D. D. Mosser, and R. I. Morimoto. 1998. Molecularchaperones as HSF1 -specific transcriptional repressors. Genes Dev. 12:654-666.

Sidhu, R. S., R. K.Sharma, A. J. Jr. Thomas, and A. Agarwal. 1998. Relationship between creatine kinase activity and semen characteristics in subfertile men. Int. J. Fertil. Women's. Med. 43:192-197.

Srivastava, N., S. K. Srivastava, S. K. Ghosh, A. Kumar, P. Perumal, and A. Jerome. 2013. Acrosome membrane integrity and cryocapacitation are related to cholesterol content of bull spermatozoa. Asian Pac. J. Reprod. 2:126-131.

Therien, I., D. Bousquet, and P. Manjunath. 2001. Effect of seminal phospholipid-binding proteins and follicular fluid on bovine sperm capacitation. Biol. Reprod. 65:41-51.

Therien, I., R. Moreau, and P. Manjunath. 1998. Major proteins of bovine seminal plasma and high-density lipoprotein induce cholesterol efflux from epididymal sperm. Biol. Reprod. 59:768-776.

Tvrda, E., Z. Knazicka, L. Bardos, P. Massanyi, and N. Lukac. 2011. Impact of oxidative stress on male fertility-A review. Acta Vet. Hung. 59:465-484.

Ward, C. R. and B. T. Storey. 1984. Determination of the time course of capacitation in mouse spermatozoa using a chlortetracycline fluorescence assay. Dev. Biol. 104:287-296.

Watson, P. F. 2000. The causes of reduced fertility with cryopreserved semen. Anim. Reprod. Sci. 61:481-492.

Yoon, S. J., W. S. Kwon, M. S. Rahman, J. S. Lee, and M. G. Pang. 2015. A novel approach to identifying physical markers of cryo-damage in bull spermatozoa. PLoS One. 10:e0126232. 